\title{
A questão da reforma da Previdência Social no Brasil
}

\author{
VICENTE DE PAULA FALEIROS*
}

O primeiro objetivo deste artigo é o de apresentar os resultados parciais das reformas da previdência social no Brasil a partir de 1995, tendo em vista que o processo ainda não acabou. Encontra-se, por exemplo, em discussão no Congresso Nacional o projeto de previdência complementar do setor público e o de seguro de acidentes de trabalho ainda está em discussão. Além disso, o governo pretende reapresentar o desconto para a Previdência Social dos aposentados do setor público, desta vez com uma alíquota semelhante à dos trabalhadores na ativa. Tem como horizonte de médio prazo transformar a previdência social em regime de capitalização, como acontece no Chile, mas isto depende da correlação de forças no Parlamento.

O segundo objetivo é o de demarcar a reforma da previdência no contexto mais geral da reforma do Estado e no contexto das mudanças econômicas, no chamado processo de globalização e de seu impacto nos Estados nacionais e nas políticas sociais. Em primeiro lugar vamos situar as mudanças no capitalismo pós-fordista e as exigências de um novo pacto social.

Para relevar as mudanças no capitalismo contemporâneo tomamos, na busca do mais fundamental, quatro dimensões interligadas: as formas 
de produção, a regulação salarial, o papel do capital financeiro e o papel do Estado.

Para compreender as novas formas de produção do capitalismo, Teixeira (2000) chama a atenção para a cooperação complexa, típica, segundo ele, da atual fase do capitalismo. Pretende discutir se a luta de classes continua ou não, confrontando-se com alguns teóricos, como Giannotti, que preconizam o fim da sociedade do trabalho. Teixeira apreende o capitalismo contemporâneo como uma nova fórmula de produção de mercadorias na qual se torna sujeito quase absoluto, como força social mais dominante que nunca e que a cooperação complexa restabelece o domínio do capital sobre o trabalho, este como fonte viva do valor tornando a correlação de forças entre capital e trabalho ainda mais assimétrica com a ameaça maior do desemprego. A cooperação complexa é uma forma de acumulação sem desenvolvimento pela globalização do capital, em que não se trata apenas da ampliação da escala da produção de mercadorias mas de um "revolucionamento" da divisão social do trabalho, com novas formas de organização e gerenciamento do processo de trabalho para racionalizar e potencializar o consumo produtivo da força de trabalho através das reestruturações produtivas. Isto implica uma investida contra a legislação trabalhista, e o afastamento do Estado das negociações trabalhistas. Podemos deduzir que haverá mudanças na previdência que venham se inscrever nas novas relações de produção.

As mudanças na regulação salarial, segundo Giuseppe Cocco não afetaram o trabalho vivo, que continua fundamental para o capital. Na sua perspectiva da teoria da regulação mostra que as mudanças nas relações salariais sob a hegemonia norte-americana e as mudanças no Estado desenvolvimentista na América Latina ou nas economias periféricas implicam novas relações salariais e que o Estado fordista que representava uma organização da regulação salarial entra em crise, pois pressupunha um alto nível de presença da classe operária e o simultâneo incremento de composição orgânica do capital e dos ganhos de produtividade. Nessa perspectiva, Cocco retoma a tese da cidadania industrial segundo a qual a relação salarial implicava o acesso aos direitos sociais. 
Na fase atual do capitalismo, há uma queda dos ganhos de produtividade e também maior constrangimento do exterior, com a globalização promovendo a desterritorialização do capital e a flexibilidade do trabalho provocando uma crise do Estado e caracterizando o paradigma pós-fordista como "uma paradigma social que se qualifica pela integração produtiva dos consumidores como produtores, pois eles participam da produção, desde o momento da concepção, em dois níveis: pela integração em tempo real dos comportamentos de consumo; e pela proliferação disseminada dos atos criativos, lingüísticos e comunicativos" (Cocco, 2000, p. 87). Esta mudança implica uma resposta à demanda interna por uma oferta mundial, mudanças táticas das forças em campo com recuo nas reinvindicações salariais e o crescimento não inflacionista com deslocamento do capital de um mercado para outro, implicando nova qualidade do trabalho vivo. Podemos inferir que as formas de constituição dos fundos e prestações também entram em crise, pois o próprio desconto em folha tende a diminuir com a diminuição do trabalho industrial estável.

O capitalismo contemporâneo implica mudanças na articulação territorial da produção, e ao mesmo tempo, novas formas de contrato como a terceirização e aprecarização (Faleiros, 1999), com novas relações das multinacionais num espaço de integração real e virtual. Nesse sentido Cocco chama a atenção para o trabalho imaterial pois "o sistema de produção se identifica com o processo de produção da comunicação social, pois integra a comunicação na produção, sendo importante considerar o que Jean Lojkine chama de "revolução informacional". Não se trata de uma mudança tecnológica superficial, mas da própria organiżação produtiva.

Nesse contexto de mudanças não só a produção muda, mas a organização geral do capitalismo e das formas de acumulação pelo lucro finance.ro, pois as empresas se "valorizam" de acordo com o valor de suas ações e de seus papéis. E necessário salientar o papel predominante do capital financeiro e especulativo numa economia que movimenta bilhões dedolares em alguns minutos no mundo inteiro e deixa pendente das bolsas as decisões conjunturais, como a valorização ou desvalorização das moedas e ações. Todos os dias a imprensa noticia: "o mercado está 
nervoso" ou "o mercado está calmo", ou seja, por trás destas constatações bursáteis existe um jogo pesado para obtenção de lucros ou rendimentos das aplicações nas quais, inclusive, muitos trabalhadores e fundos de pensão puseram suas economias. Há uma forte pressão para que os países periféricos paguem juros ao preço de ver destruídas suas economias e suas fontes de produção. O próprio capital financeiro se descola da produção e da reprodução da força de trabalho. Os ganhadores e os perdedores nessas transações podem ter somas elevadas envolvidas, mas os grandes capitais que detêm a informação privilegiada têm mais condições de manter seus ganhos e provocar mais exclusão social. Desta forma, a produção está vinculada não só à complexidade e à virtualidade, mas à especulação, criando-se fundos que privilegiam uns poucos aplicadores, rompendo-se a lógica da solidariedade dos fundos proveniente da regulação fordista.

Além destas três dimensões fundamentais das mudanças no capitalismo contemporâneo, ou seja, o predomínio e a ampliação das fronteiras da produção de mercadorias de forma complexa com a presença do processo de comunicação, de inteligência na produção, de novas regulações salariais e do capital financeiro, as relações de classe estão mudando no processo de garantia dos fundos públicos e dos direitos sociais pelo Estado de cidadania, tornando ainda mais complexa a realidade do capitalismo contemporâneo.

No capitalismo fordista, caracterizado pela produção em série em unidades territorializadas foi possível, ao mesmo tempo, a organização dos trabalhadores e uma socialização dos custos da reprodução da força de trabalho através da negociação tripartite entre sindicatos, Estado e empresários. Os conflitos nas empresas por melhorias salariais eram visibilizados e passíveis de negociação pelos interlocutores em presença, os empresários e os trabalhadores organizados local ou territorialmente no âmbito do Estado/nação. Através de um pacto econômico-político foi possível a constituição de fundos públicos que garantissem, ao mesmo tempo, as condições de acumulação do capital e as condições de reprodução da força de trabalho. Os fundos são a base da Previdência Social tal como a conhecemos e tal como foi implementada na quase 
totalidade dos países do mundo. A Previdência possibilitou não só a compensação pelos riscos de doença, velhice, acidente e invalidez, mas criou um sistema forte de coesão social, capaz de fazer aceitar a exploração capitalista. Possibilitou também a circulação da mão-de-obra entre as empresas e entre países, pois o mesmo fundo servia a várias empresas e vários tipos de trabalho, ou melhor, a vários tipos de emprego (Faleiros, 2000).

Francisco de Oliveira (1988) chama a atenção para o fato de que no contexto fordista existe um processo de mútuo reconhecimento e mútua vantagem para empresários, Estados e trabalhadores na constituição do fundo público da previdência social e denomina essa forma de "modo social-democrata de produção". Hoje Oliveira chama a atenção para a unificação da classe dominante e da classe dominada criando a virtualidade de um campo hegemônico e fortalecendo a hegemonia burguesa, aumentando a exclusão social e o totalitarismo com a destruição dos direitos sociais (Oliveira, 1999).

Podemos dizer que há uma crise de "interlocutoriedade", um esgarçamento do pacto de negociação pelo enfraquecimento da forma de organização sindical e patronal e criação de grupos multinacionais decisionais que passam por cima dos Estados e das organizações com base nas empresas localizadas. Os Estados e as empresas continuam tendo um papel significativo, mas devem se enfrentar estrategicamente com as decisões multinacionais.

Há um consenso sobre a realidade das profundas mudanças no capitalismo contemporâneo e de seus impactos não só na produção mas na vida cotidiana e no Estado. No cotidiano, o impacto do desemprego é o mais visível e, no Estado, percebe-se a redução dos direitos sociais. Desta forma, não se pode desvincular a reforma da previdência do novo papel do Estado neste contexto de mudanças no capitalismo contemporâneo. O fundo público fordista já não garante mais a inclusão dos trabalhadores e a cidadania industrial está em colapso, pois o fundo apenas incluía aqueles que possuíam um contrato de emprego. $\mathrm{O}$ trabalho precário, o trabalho informal e o trabalho terceirizado, além da flexibilização dos contratos não garantem a estabilidade e a base necessárias para a 
constituição de um fundo baseado em descontos salariais e contribuições empresariais. Os direitos trabalhistas passam por profundas mudanças e as políticas hoje formuladas para enfrentar as novas condições do capital são focalizadas num pretenso credo ideológico de que o indivíduo e a sociedade são os responsáveis pela sua subsistência e condições de trabalho.

As reformas da previdência social se inscrevem num processo contraditório em que os trabalhadores lutam por garantir direitos, entre eles o direito à vida, num contexto democrático e num Estado de direito, e os grandes negócios e o capital financeiro promovem uma política de eliminação e de redução de direitos para sustentar com mais força as bases de uma produção complexa, sem salários estáveis, financeirizada e com fundos privados ao invés dos fundos públicos, e com um Estado desregulamentado. As reformas da previdência social no Brasil, não são pois, meros arranjos conjunturais para um equilíbrio de caixa, como apregoa o governo, mas um processo de refundação das relações de acumulação e das relações de classe.

\section{Refundação capitalista das políticas sociais}

Para não retomar aqui o que já analisamos alhures (Faleiros, 1999, 2000), podemos demarcar essa refundação capitalista nas políticas de privatização, de financeirização dos fundos, de desregulamentação dos direitos trabalhistas (em nome da flexibilização), de promoção da empregabilidade (capacitação) e de focalização e de estímulo ao trabalho.

Nesse contexto é enfatizado o workfare, ou seja, o condicionamento de um melhor benefício ou do auxílio social a uma formação ou inserção no trabalho e também a capacitação para o trabalho. Desta forma o trabalho está no centro das políticas sociais contemporâneas, num contexto de redução do emprego industrial, parecendo ser esta uma das principais contradições das novas formulações de políticas sociais. Estão se tomando predominantes os trabalhos precários e terceirizados sem vínculo empregatício estável, o que responsabiliza o próprio trabalhador individualmente pelo pagamento de contribuições a um fundo de aposentadoria ou saúde. 
Ao mesmo tempo, o Estado passa para o mercado e/ou para a sociedade serviços e fundos públicos constituídos na regulação fordista. A nova regulação traz no seu bojo uma redefinição da gestão e da constituição dos fundos para a manutenção do trabalhador.

Privilegiam-se os fundos privatizados e financeirizados, isto é, inseridos na lógica do capital financeiro, vinculando-os aos bancos na perspectiva de sua capitalização através de aplicações financeiras. ${ }^{1}$ A lógica da solidariedade entre gerações ou entre grupos sociais como os sadios e os doentes é substituída pela lógica da competitividade individual. A contribuição aos fundos privados depende do indivíduo e se refere exclusivamente à sua contribuição individual ao longo dos anos. A remuneração dessa contribuição fica nas mãos dos gestores privados, apenas acompanhados por um controle de burocratas do Estado. Esse controle está sendo organizado através de agências governamentais que nem sempre atendem ao cidadão mas se vinculam à garantia da melhor situação para o capital, por exemplo mantendo tarifas e juros que lhes sejam favoráveis.

Exemplo disso são as indexações autorizadas pelas agências para que as empresas privatizadas aumentem seus preços, muito acima dos reajustes ou das situações salariais, muitas sem reajustes, como a dos funcionários públicos federais.

\section{Fundos privados complementares e de seguros de acidentes do trabalho}

Os fundos privados não têm a garantia total do Estado e ficam à mercê das aplicações, podendo os trabalhadores perder suas economias, como já aconteceu com a Capemi (Caixa de Pecúlio dos Militares) nos anos 70 .

No Brasil, a discussão e a implementação da previdência complementar está vinculada diretamente ao reforço dado aos seguros

Mesmo na Suécia, modelo social-democrata, uma pequena parte dos fundos (2\%) tornou-se capitalizada. 
privados, não raro vinculados ao capital internacional. Já está autorizado o desconto das aplicações em fundos privados do Imposto de Renda (até certo limite) o que promove uma renúncia fiscal, ou seja o financiamento público de um fundo privado.

A reforma do seguro contra acidentes do trabalho, proposta pelo governo, já foi contemplada na Emenda Constitucional n 20 de 1998 (Constituição Federal, art. 201, § 10), determinando que "aLei disciplinará a cobertura do risco de acidente do trabalho, a ser atendida concorrentemente pelo regime geral de previdência social e pelo setor privado". Para isto o governo criará as Administradoras de Riscos do Trabalho (ADARTs), que oferecerão, pelo prazo de dois anos, a contar do dia do acidente todo o leque de benefícios como subsídio por invalidez, ficando a aposentadoria a cargo do INSS. A ADART só se responsabilizaria pelo acidente durante dois anos. De todas as maneiras como assinala o Secretário de Previdência Social "para a previdência social o que reza é o caráter contributivo" e a previdência poderia prover benefícios e a ADART ficaria com parcelas indenizatórias (Schubert e Pinheiro $^{2}$,2001). O financiamento seria feito através de prêmio pago pela empresa, fixado mediante plano de custeio variável e com contribuições para o INSS atreladas ao prêmio. Haveria um fundo de solidariedade para situações residuais e um controle por agências reguladoras, mas a gestão seria feita através do órgão privado. Além do mais, a assistência à saúde seria feita em parceira com o Sistema Único de Saúde (SUS). Desta forma, os principais gastos ficam remetidos ao sistema público e pode-se prever que as situações mais graves e mais onerosas fiquem também para o sistema público.

O objetivo declarado do governo é o de reduzir custos e "rivalizarse, existir-se simultaneamente, competir e estabelecer seguradoras com fins lucrativos ou mútuas sem fins lucrativos". Declara também o governo que pretende impor o ressarcimento ao SUS pelo atendimento e estabelecer planos de prevenção de acidentes, mas o núcleo da mudança está na privatização e na transformação dos fundos públicos em fundos privados.

2 Baldur Schubert e Vinícius Carvalho Pinheiro são respectivamente Gerente de Projetos do INSS c Secretário de Previdência Social do MPAS. 


\section{A reforma da previdência para os trabalhadores do setor privado}

A reforma da previdência social brasileira, debatida no Congresso Nacional de 1995 a 1998, passou por um enfrentamento de projetos e de interesses (Faleiros, 2000b; Vianna, 1998; Melo, 1996) não raro divergentes, implicando pressões e contra pressões tanto dentro como fora do Parlamento. Nesse debate, que aqui não vamos detalhar, o resultado foi que o sistema contributivo passou a figurar para o setor privado e o sistema público passou a ter critérios muito mais rígidos de controle e de financiamento. A ênfase no sistema contributivo, ao invés de se considerar o tempo de trabalho teve o objetivo de diminuir o déficit nas contas do governo, cuja prioridade é o pagamento de juros (financeirização) e uma articulação com o setor privado para implementação dos fundos privados.

Para os trabalhadores do setor privado, pela emenda constitucional de $\mathrm{n}^{\circ} 20$, ficou estabelecido o seguinte:

- Regime geral de caráter contributivo para cobertura de eventos de doença, invalidez, morte e idade avançada, proteção à maternidade, proteção ao trabalhador em situação de desemprego involuntário, salário família, pensão por morte. Não há mais critérios diferenciados para concessão de aposentadoria no Regime Geral, a não ser com prejuízo da saúde e da integridade física.

- Salário família para trabalhador de baixa renda e não para todos.

- Proibição de trabalho a menores de 16 anos.

- Gestão quadripartite nos órgãos colegiados.

- Financiamento de empregadores, da empresa e da entidade a ela equiparada considerando a folha de salários e demais rendimentos do trabalho pagos ou creditados a qualquer título à pessoa física que lhe preste serviços, mesmo sem vínculo empregatício; receita ou faturamento; lucro. Financiamento dos trabalhadores. Receita de concursos e prognósticos. Alíquota de produtores parceiros, meeiros e arrendatários rurais e pescadores artesanais sobre o resultado da comercialização. 
- Manutenção do piso de um salário mínimo e reajuste na forma da Lei.

- Proibição de segurado facultativo a quem já tenha regime próprio de previdência.

- Extinção da aposentadoria proporcional por tempo de serviço na área pública e no regime geral de previdência social.

- Garantia da aposentadoria:

- com 35 anos de contribuição, se homem, e 30 anos de contribuição, se mulher.

- Com 65 anos de idade se homem, e 60, se mulher, reduzindose em cinco anos o limite para os trabalhadores rurais e para os que exerçam suas atividades em regime de economia familiar.

- Redução de cinco anos para o professor primário ou secundário.

- Contagem recíproca do tempo de contribuição nos diferentes regimes.

- Caráter facultativo para a previdência complementar.

- O contrato de trabalho exclui as contribuições dos planos de entidades de previdência privada.

- Possibilidade de fundo para pagamento de benefícios além dos recursos de sua arrecadação.

- Garantia dos direitos adquiridos até a data da publicação da emenda com base nos critérios da legislação então vigente.

- Estabelecimento de regras de transição.

- Estabelecimento do valor máximo de $\mathrm{R} \$ 1.200,00$ para a aposentadoria e de R \$ 360,00 para obter salário-família.

O governo pretende também mudar a forma de contrato dos servidores públicos passando-a, em grande parte, para a regulamentação pela Consolidação das Leis do Trabalho (CLT), ou seja, sem as garantias do serviço público, expressas no Regime Jurídico Único. A Lei n ${ }^{\circ}$ 9.962/ 
2000 permite o emprego público com com vinculaçâo ao Regime Geral da Previdência Social. ${ }^{3}$ Com esta perspectiva, o contrato do servidor público seria regulamentado da mesma forma que o do setor privado, obrigando o servidor que quisesse ir além da aposentadoria mínima a contratar a previdência complementar. Um exemplo típico desta transformação, é o anteprojeto de lei de emprego público nas instituições federais de ensino proposto pelo Ministério da Educação em 22 de janeiro de 2001. O artigo segundo do referido anteprojeto reza: "os empregos criados na forma desta Lei reger-se-ão pelo regime de contratação da Consolidação das Leis de Trabalho".

Desta forma, haverá no serviço público uma dualidade de funcionários, uns estáveis e com aposentadoria integral e outros instáveis com aposentaria limitada para fazer o mesmo tipo de trabalho.

As regras estabelecidas pela Emenda 20 provocaram uma mudança significativa do tempo de trabalho, previsto na Constituição de 1988, para o tempo de contribuição, ou seja, dando um caráter de seguro social e não de seguridade. O objetivo da reforma é de aproximá-la, o máximo possível, das regras do mercado. Aliás, o projeto inicial do governo visava reduzir o teto das aposentadorias para o nível próximo de três a cinco salários mínimos, o que não foi alcançado graças às pressões dos movimentos sociais.

Após aprovação da Emenda, o governo estabeleceu, através da Lei $\mathrm{n}^{\circ}$ 9.876, de 26 de novembro de 1999, o fator previdenciário que consiste numa mudança no cálculo das prestações dos benefícios. Estes eram baseados nos últimos 36 meses e passaram a ter uma base que corresponde a $80 \%$ das remunerações de toda a vida laborai dos segurados considerando o tempo de contribuição, a alíquota e a expectativa de sobrevida do segurado no momento da aposentadoria. E o novo método implica uma estimativa do montante de contribuição capitalizado, conforme taxa pré-determinada que varia em razão do tempo de contribuição e da idade do segurado e da expectativa de duração do

\footnotetext{
${ }^{3}$ Uma consolidação da legislação federal sobre previdência do setor público foi feita pelo Ministério da Previdência e da Assistência Social e pode ser consultada Ministério da Previdência e Assistência Social (2000).
} 
benefício.

Com o fator previdenciário, os segurados perdem dinheiro em seus benefícios, alongando-se o perfil dos que podem entrar na aposentadoria, nivelando-se por baixo os benefícios.

A questão da idade do ingresso na aposentadoria tem sido um dos temas mais disputados e polêmicos da reforma da previdência, argumentando os defensores de uma idade mínima elevada que não se deve pagar benefícios àqueles que estejam em idade de trabalhar e os contrários afirmando que, no Brasil, é mais justo o regime de tempo de trabalho, pois o ingresso na atividade laborai começa muito cedo. Isto justificaria uma aposentadoria por tempo de trabalho e não por idade. Esta norma continua válida para aqueles que tem seu direito adquirido dentro das regras de transição.

O fator previdenciário, no entanto, veio desconsiderar a questão do tempo de trabalho e privilegiar a idade. Esta questão demográfica é bastante complexa tendo em vista que a população brasileira vai ter um contingente de idosos bastante elevado, diminuindo a proporção de ativos em relação aos inativos. A esperança de vida em 2000 é de 66,47 anos para os homens e de 72,6 para as mulheres, devendo passar em 2005 para 66,4 para os homens e 72,6 para as mulheres. No regime geral de previdência na década de 70, havia 4,2 contribuintes para um aposentado; na década de 90, havia 2,5. As taxas de fecundidade passaram de 5,8 em 1970 para 2,6 em 1991 e a estrutura etária deverá ter outra conformação em poucos anos passando o percentual de idosos (pessoas com mais de 65 anos) de 4\% em 1980 para 5,4\% em 1996 e devendo alcançar $11 \%$ do total da população em $2020 .^{4}$

Na reforma da Previdência os critérios demográficos e atuariais serviram de pano de fundo para o discurso, pois não foi a partir deles que a discussão se entabulou, mas a partir da dívida a ser paga e cujo pagamento deveria recair sobre os contribuintes e não sobre o capital. $\mathrm{Na}$ argumentação governamental, o capital já estaria por demais onerado com o "custo Brasil" que lhe retiraria competitividade no contexto da

4 Dados do IBGE citados por Stephanes (1998). 
globalização. Ou seja, as formas globalizadas de produção complexa e as novas regulações salariais e financeiras fazem os ônus recaírem "naturalmente" 5 sobre os trabalhadores.

A questão fundamental da desigualdade social e de seu combate não foi ventilada no processo da reforma da previdência, pois o capital financeiro só faz acentuá-la, o que corresponde à lógica dos fundos privados.

Foi na contramão dessa lógica que as pressões sociais levaram a que se estabelecesse, na Constituição de 1988, uma redistribuição de renda dos trabalhadores urbanos para os trabalhadores rurais, ao incluir estes últimos nos benefícios da aposentadoria sem que houvessem contribuído para ela de forma sistemática. Foi uma das maiores conquistas no processo de redistribuição de renda, incorporando em torno de 6 milhões de trabalhadores do campo no benefício de um salário mínimo e trazendo até mesmo um forte impacto econômico em municípios muito pobres (França, 1999). O volume de benefícios pagos pela Previdência em 57,3\% dos municípios, é maior do que o que eles recebem do Fundo de Participação dos Municípios (FPM), segundo dados de 1997.

Dos 18,3 milhões de beneficiários da Previdência, $64,4 \%$ ou 11,8 milhões percebem o piso previdenciário em 1998, configurando-se a desigualdade de acesso a ela, pois o piso de um salário mínimo (no valor de US\$ 83,00 em abril de 2001) mal permite a subsistência mensal de um adulto. $\mathrm{O}$ piso previdenciário não tem, em si mesmo, um caráter redistribuo' vo entre ricos e pobres, o que deveria ocorrer com o benefício da Lei Orgânica da Assistência Social, que se restringe aos portadores de deficiência e aos maiores de 67 anos extremamente pobres, isto é cuja renda mensal familiar não ultrapasse um quarto de salário mínimo per capita.

Outra das questões não resolvidas pela Reforma da Previdência foi a incorporação dos trabalhadores sem carteira de trabalho ao regime previdenciário, pois deverão contribuir para os fundos privados ou públicos 
a partir de suas remunerações, para obter qualquer benefício de aposentadoria. $\mathrm{O}$ acesso à saúde, no Brasil, é universal, mas de qualidade sofrível quando acionado.

Calcula-se que existam em torno de 33,3 milhões de pessoas ocupadas no setor privado sem cobertura no INSS, ou seja, 59,4\% do total de ocupados. Dados da PNAD-98 citados por Cechin ${ }^{6}$ (2000) mostram que existiam apenas 4,7 milhões de contribuintes individuais, 925,8 mil domésticos, 2,0 milhões de autônomos, 1,1 milhão de empregadores e de 18,0 milhões de empregados celetistas de empresas, totalizando 22,8 milhões de contribuintes numa PEA de 76,8 milhões. Dos 12,3 milhões de empregados sem carteira, apenas 8,8\% são segurados do INSS. Dos 16 milhões de autônomos, apenas 16\% são segurados.

$\mathrm{O}$ acesso à Previdência Social não se consolidou com a reforma, pois reflete a desigualdade social. Quanto maior a renda, maior também o nível de incorporação à Previdência Social. O governo tenta maquiar a facilidade de acesso com a instalação de escritórios computadorizados aos quais só têm acesso, também, os que conhecem os meandros da digitação e são neles alfabetizados. Note-se que no país existem ainda $16 \%$ de analfabetos.

Para a solução do déficit previdenciário não se considera, de forma séria e responsável, o combate à sonegação, que é muito elevada, pois segundo a Associação de Fiscais da Previdência (ANFIP), a evasão na área da receita previdenciária situa-se em torno de 30 a $40 \%$ de seu potencial. Por exemplo, em 1997 foram arrecadados diretamente de empresas e trabalhadores $\mathrm{R} \$ 48$ bilhões, mas poderiam ter sido alcançados $\mathrm{R}$ \$ 78 bilhões. Esses R \$ 30 bilhões são decorrentes de sonegação, fraude ou evasão fiscal. (ANFIP, 1997).

Apesar de novos mecanismos de arrecadação e de inibição da sonegação a reforma não possibilitou a quebra do sigilo fiscal dos sonegadores e ainda deixa a desejar no combate às fraudes, dificultandose a fiscalização das empresas que adotam o SIMPLES, o imposto único para as pequenas empresas. Faltam fiscais para a fiscalização

6 José Seehin é secretário executivo do MPAS. 
previdenciária, devendo-se estimular a cooperação entre os diferentes órgãos para a fiscalização.

\section{A reforma do setor público}

Um dos principais alvos do governo para a reforma da Previdência foi a mudança das aposentadorias no setor público ao qual se referiu sempre como causador de déficits, lugar de privilégios, e acolhedor de facilidades e vantagens para si em detrimento da sociedade. A desqualificação do servidor público tem justificado, inclusive, um arrocho salarial sem precedentes pois estes não receberam reajuste nos últimos 6 anos, calculando os sindicatos uma defasagem de aproximadamente $75 \%$ em 2001.

Uma das questões mais complexas e disputadas na reforma foi a contribuição dos inativos, tendo o governo apresentado a questão quatro vezes no Parlamento, ${ }^{7}$ sendo derrotado em três e conseguindo a aprovação da contribuição na crise de 1999, através da Lei n ${ }^{\circ}$ 9.783/99, mas sofreu com derrota na Justiça, pois o Supremo Tribunal Federal, em ação liminar, considerou o desconto como um confisco. ${ }^{8}$

Em vários Estados da União existe contribuição de inativos, inclusive diferençada por faixa de renda. De acordo com o Relatório Anual da Previdência Social de 1999 (p. 764) a contribuição dos aposentados é de 3,5\% em Minas Gerais, de 4 a 5\% no Acre, de 5\% na Bahia, de 6\% em São Paulo, de 7,4\% no Rio Grande do Sul, de 8\% em Roraima, de 9\% em Tocantins, de $11 \%$ no Rio de Janeiro, de 8 a $12 \%$ em Santa Catarina e Mato Grosso, de 11 (até R\$ 1.200,00) a 20\% no Amazonas, de 10 (até R\$ 1.200,00) a 20\% no Paraná e de 10 (até $\mathrm{R} \$ 200,00$ ) a $20 \%$ (acima de R \$1.200,00) em Pernambuco. Não havia contribuições em Roraima, Pará, Amapá, Piauí, Ceará, Rio Grande do Norte, Paraíba, Alagoas, Mato Grosso do Sul, Goiás e Distrito Federal. Como existem ações na Justiça relativas a essas contribuições, a situação pode ter mudado.

\footnotetext{
Medidas Provisórias 560/95, $1.415 / 96$ c 1.482/98 e Lei $n^{\circ}$ 9.783/99. Esta lei foi questionada por Ação Direta de Inconstitucionalidade 2.010-2.

Mandado de Segurança 23.411-DF.
} 
Alguns Estados (12) também impõem contribuições aos pensionistas. Em 1998, a União gastou 20,4 bilhões com o pagamento de aposentados e pensionistas, e os Estados 17,7 bilhões, tendo arrecadado, respectivamente, 3,1 e 3,4 bilhões. Não há nesse Relatório, dados de gastos dos municípios, mas anota-se que 2.281 municípios têm previdência municipal, abrangendo 1.283.599 servidores.

O discurso da defasagem entre contribuição e gasto é constantemente usado pelo governo para defender a contribuição dos aposentados, sem considerar a história da Previdência Social do servidor público. A previdência do servidor público faz parte de um contrato público de trabalho, regulado em lei, que não the impunha contribuição. Esta exigência de contribuição, inclusive para os que já se aposentaram, faz parte do processo de oneração do trabalho em benefício do que hoje se considera o dever sagrado do Estado: "o pagamento dos juros ao capital financeiro". A sociedade não foi consultada sobre esta mudança e nem houve negociação com os trabalhadores, buscando o governo dividir as forças sindicais organizadas, conversando com um segmento (Força Sindical) e desconversando com o outro (CUT).

Apesar das derrotas sofridas quanto à contribuição dos inativos, o Governo mudou completamente as condições da aposentadoria no setor público com as seguintes modificações através da Emenda $n^{\circ} 20$ :

- Previdência com caráter contributivo.

- Fim da aposentadoria proporcional, a não ser por invalidez.

- Cumprimento do prazo de 10 anos no serviço público e de 05 no cargo efetivo.

- 60 anos de idade e 35 de contribuição para homem, e 55 de idade e 30 de contribuição, se mulher.

- Proventos proporcionais ao tempo de contribuição com 65 e 60 anos de idade respectivamente, homem e mulher.

- Proibição de aumento em relação ao que teria no cargo efetivo.

- Totalidade da remuneração. 
- Proibição de critérios diferenciados, exceto em condições que prejudicam a saúde.

- Redução de idade para professor primário ou secundário.

- Revisão das remunerações na forma da Lei.

- Teto para aposentadoria de acordo com a reforma administrativa.

- Proibição de contribuição do Estado às entidades acima da contribuição do segurado.

- Disciplinamento por Lei da relação entre o Estado e entidades de previdência.

Além destes requisitos da Emenda $\mathrm{n}^{\circ} 20$, a Lei Complementar $\mathrm{n}^{\circ}$ 101, de maio de 2000, denominada de Responsabilidade Fiscal, estabelece normas de finanças públicas e controle dos gastos públicos, inclusive referentes às despesas com pessoal, com limites claros para cada esfera de governo (União, Estados e Municípios) e para cada esfera de poder (Executivo, Legislativo e Judiciário). A Lei estabelece também que nenhum benefício ou serviço relativo à seguridade social poderá ser criado, majorado ou estendido sem a indicação da fonte de custeio total (Art. 24).

A Lei $\mathrm{n}^{\circ}$ 9.717, de 27 de novembro de 1998, estabeleceu critérios claros para a organização e o funcionamento dos regimes próprios de previdência social dos servidores públicos da União, dos Estados, do Distrito Federal e dos Municípios, dos Militares dos Estados e do Distrito Federal.

Com esta lei fica configurada a necessidade de um regime atuarial para a previdência social pública, estabelecendo-se a contribuição dos servidores ativos e inativos para os respectivos regimes, com garantia de receita, podendo constituir-se fundos integrados de bens, direitos e ativos com finalidade previdenciária. O Ministério da Previdência deve acompanhar rigorosamente cada regime de previdência pública.

A Lei $n^{\circ}$ 9.796, de 05 de maio de 1999, estabelece as regras para a compensação entre os diferentes regimes de previdência social com regras bem precisas de acordo com o estabelecido na Constituição e nas 
Leis. Os entes públicos também poderão parcelar as suas dívidas para com o INSS de acordo com a Lei n 9.639, de maio de 1998.

As mudanças da previdência no setor público mostram claramente o viés de responsabilização do servidor pela sua própria previdência, sendo o Estado apenas um caixa-mor dos benefícios e não um sistema de garantia de direitos. E neste novo paradigma que se pretende fundar a previdência do setor público. Com a contratação de servidores pela CLT, todos serão igualados por baixo.

\section{Alguns elos de conclusão}

A reforma da Previdência Social não passou tão facilmente pelo Congresso Nacional como as reformas econômicas para privatização dos sistemas de cabotagem, exploração mineral, energia elétrica, de petróleo e dos sistema de telecomunicações. Segundo o governo, no Plano Diretor de Reforma do Estado (1995) não cabe mais ao Estado atuar no sistema produtivo e de desenvolvimento do país, pois a crise do Estado, para o governo, advém do fato de "não saber superar a sobrecarga de demandas a ele dirigidas. A desordem econômica expressava agora a dificuldade do Estado em continuar a administrar as crescentes expectativas em relação à política de bem-estar aplicada com relativo sucesso nos pós-guerra". Além disso o Plano assinala que o "Estado concentra funções e se caracteriza pela rigidez dos procedimentos e pelo excesso de normas e regulamentos." Em outras palavras, a crise do Estado advém do fato de ser Estado, isto é, gerir o pacto social de cidadania, para não mais cuidar das expectativas de bem-estar que o sobrecarregam, portanto, para tornálo mais ágil para o capital, e conforme o Plano citado com: "ajuste fiscal, reformas econômicas referenciadas ao mercado, para elevar sua capacidade competitiva, reforma da previdência social, inovação dos instrumentos (sic!) de política social, proporcionando maior abrangência e promovendo melhor qualidade para os serviços sociais e reforma do aparelho do Estado com vistas a aumentar sua governança, ou seja sua capacidade de implementar de forma eficiente políticas públicas." 
Apesar do discurso da abrangência das políticas sociais, não se explicita que seus instrumentos são os fundos privados, pois o objetivo dessa refundação capitalista do próprio Estado é reduzi-lo, é ampliar o mercado, aumentar a competição, como fica bem claro no enunciado do Governo.

A reforma da Previdência Social, no Brasil, processa-se numa correlação de forças de predomínio de um bloco neoconservador no poder, com discurso modernizante e políticas vinculadas ao Fundo Monetário Internacional.

A refundação do Estado na lógica do capital internacional está sendo confundida, pelo governo, com o estabelecimento de certas regras para a Previdência Social, que poderiam mudar para adequá-la ao novo perfil demográfico, social e econômico. No entanto, o véu da mudança está a obscurecer os seus fundamentos. A estes é que é preciso dar mais atenção, como tentamos fazer neste artigo.

\section{Bibliografia}

ANFIP. Sonegação, fraude e evasão fiscal. Brasília: ANFIP, 1997. v 1. BRASIL. Presidência da República. Plano Diretor da Reforma do Estado. Brasília: MARÉ, 1995

CECHIN, José. Crescimento, emprego e previdência social. Conjuntura social, Brasília, v. 11, n. 2, p. 21-68, abr-jun, 2000.

COCCO, Giuseppe. Trabalho e cidadania. São Paulo : Cortez, 2000.

FALEIROS, Vicente de Paula. Desafios do serviço social na era da globalização. Serviço social e sociedade, São Paulo, v. 20, n. 61, p. 152-186, nov. 1999.

2000a.

. A política social do Estado capitalista. São Paulo: Cortez,

. Previdência social e sociedade; relatório final de pesquisa Brasília: CNPq, 2000b. Fotocópia. 
FRANÇA, Álvaro Sólon de. A previdência social e a economia dos municípios. Brasília: ANFIP, 1999.

MELO, Marcus André B. C. de. As reformas constitucionais e a previdência social -1993-1996. In: DINLZ, Eli; AZEVEDO, Sérgio de (Orgs.). Reforma do Estado e democracia no Brasil. Brasília: UnB/ENAP, 1997. p. 295-348.

MINISTÉRIO DA PREVIDÊNCIA E ASSISTÊNCIA SOCIAL. Previdência no Serviço Público : consolidação da Legislação Federal. Brasília: MPAS, 2000.

OLIVEIRA, Francisco de. Da "democracia" ao totalitarismo. Praga, São Paulo, n. 8, p. 51-60, ago. 1999.

OLIVEIRA, Francisco de. O surgimento do antivalor. Novos Estudos CEBRAP, São Paulo, n. 22, p. 8-28, out. 1988.

SCHUBERT, Baldur; PINHEIRO, Vinícius Carvalho, O seguro contra acidente do trabalho no Brasil: evolução histórica, situação atual e apresentação da proposta do projeto de lei. In: MINISTÉRIO DA PREVIDÊNCIA E ASSISTÊNCIA SOCIAL. Sistema de seguro contra acidentes do trabalho nas Américas. Brasília: MPAS/SPS, 2001. (Série debates, v. 5).

STEPHANES, Reinhold. Reforma da previdência sem segredos. Rio de Janeiro: Record, 1998.

TEIXEIRA, Francisco José Soares. O capital e suas formas de produção de mercadorias: rumo ao fim da economia política. Crítica marxista, São Paulo, n. 10, p. 67-93, jun. 2000.

VIANNA, Maria Lúcia Teixeira Werneck. A americanização (perversa) da seguridade social no Brasil. Rio de Janeiro: REVAN, IUPERJ/ UCAM, 1998. 